\title{
Pulp Fiction e a não-linearidade narrativa
}

Ao vencer a palma de ouro no festival de Cannes em 1994 e o Oscar de melhor roteiro original, “Pulp Fiction: Tempo deViolência” foi elevado à categoria decult movie instantâneo. ${ }^{1}$ Os personagens, mesmo sendo gângsteres, traficantes e assassinos profissionais, conquistaram a simpatia do púbico.

Assistir a Pulp Fiction deixa uma sensação estranha no espectador. Parece que navegamos por um hipertexto, observando diferentes histórias, todas interligadas de maneiras nem sempre óbvias. Isso enriquece a experiência do espectador, conforme a análise de Ebert:

"Like Citizen Kane, Pulp Fiction is constructed in such a nonlinear way that you could see it a dozen times and not be able to remember what comes next ${ }^{2}$. It doubles back on itself, telling several interlocking stories about characters who inhabit a world of crime and intrigue, triple-crosses and loud desperation." 3

Mesmo assim, Pulp Fiction ainda é um filme. Ou seja, registrado em um suporte (seja película ou vídeo) preso firmementeauma escala detempo eandamento. A seguir nesteartigo é discutida a estrutura das histórias do filme, uma montagem alternativa e modelos para levar Pulp Fiction para mais perto das experiências não-lineares por completo.

\section{De onde veio Pulp Fiction}

Roberto Tietzman

Publicitário \& Designer Multimídia
A inspiração para o filme veio de revistas baratas de contos e quadrinhos de detetive. ${ }^{4}$ Impressos em papel de baixa qualidade, chamavam a atenção por seu preço pequeno e por abordarem temas demistério, violênciae sexo ${ }^{5}$. Como a própria definição apresentada 
“PULP (pulp) n. 1. A soft, moist, shapeless

mass or matter. 2. A magazine or book containing luridsubjectmatter and being characteristicallyprinted on rough, unfinished paper."6

Talvez nestefato estejam plantadasas sementes da não-linearidade do roteiro de Pulp Fiction. A o representar várias histórias curtas einseri-las em uma única trama, o realizador corre o risco de fazer um filme por demais episódico, onde as noções de conseqüência e progressão dramática seperdem. ${ }^{7}$ P ulpFiction escapa destasfal hasao estabelecer diferenças entresuastramasepersonagens, masconectálas com elementos conseqüentes (ainda que misturados no tempo) edar aos personagens traços comuns.

A história conforme foi mostrada no filme

A grosso modo, um diagrama da história do filme conforme editado está na Figura 1.0 filme pode ser divido em cinco grandes partes.

A primeiradelas, umatentativa deassal to em uma lanchonete, leva aos créditos de abertura.

Na segunda, vemos Vincent Vega (John Travolta) e Jules Winfield (Samuel Jackson) rumar para um acerto decontas com devedores de seu patrão, Marsellus Wallace. Todos são mortos pel os pistoleiros, pel o menos aparentemente.

Um cartão informa o início da terceira seqüência do filme: "Vincent Vega and Marsellus Wallace's Wife". Em seu início vemosButch (BruceWillis) eM arsellusWallace ${ }^{8}$ (Ving Rhames) acertando um suborno. Vega e Jules entram no bar e - êpa! - eles estão
Figura 1: A estrutura de Pulp Fiction como foi editada.

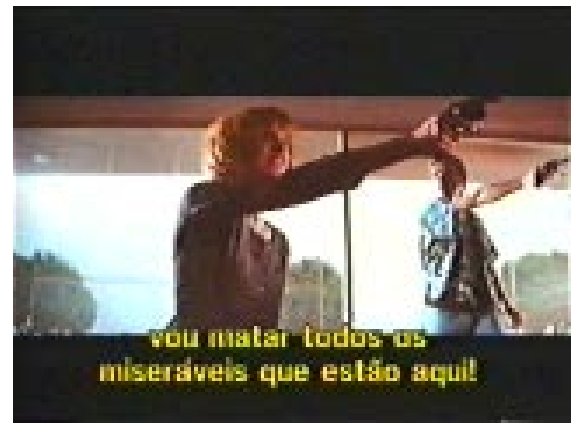

1. Cena de abertura: os assaltantes roubam uma lancheria. Ainda não sabemos, masjulese Vincent estão aí.

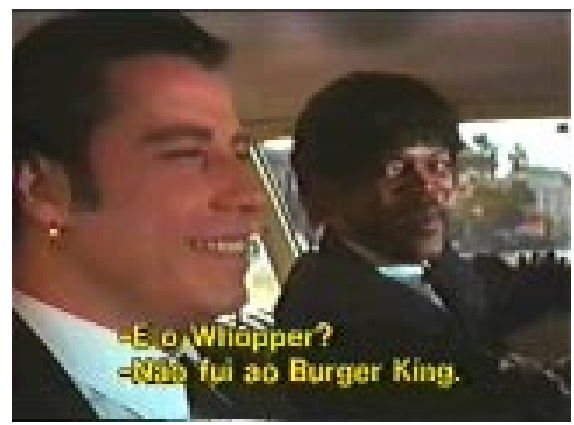

2. Jules e Vincent vão para um acerto de contas onde matarão devedores de seu patrão, Marsellus Wallace.

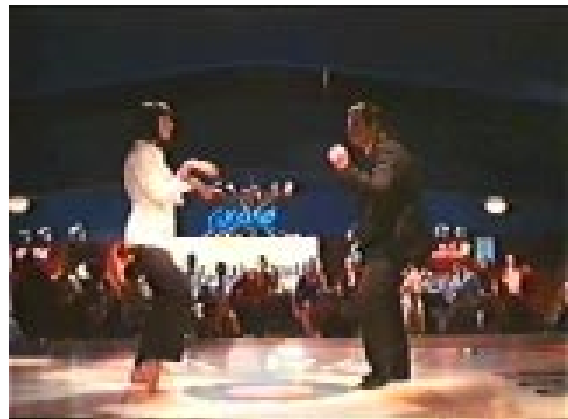

3. "Vincent Vega and Marsellus Wallace's Wife", diz o cartão no iníco da seqüência que culmina na reanimação de Mia.

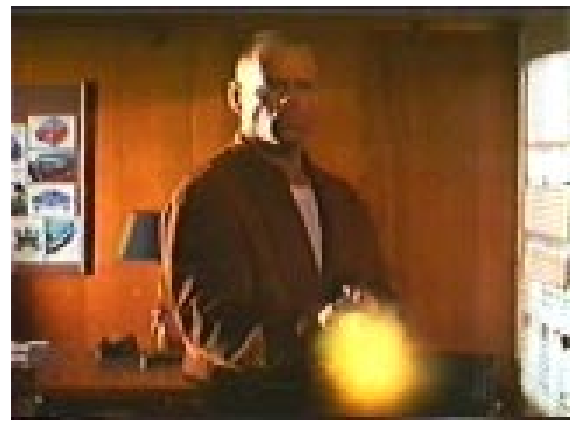

4. "The Gold Watch" mostra Butch fugindo de Marsellus por dívidas não pagas. Vincent Vega morre.

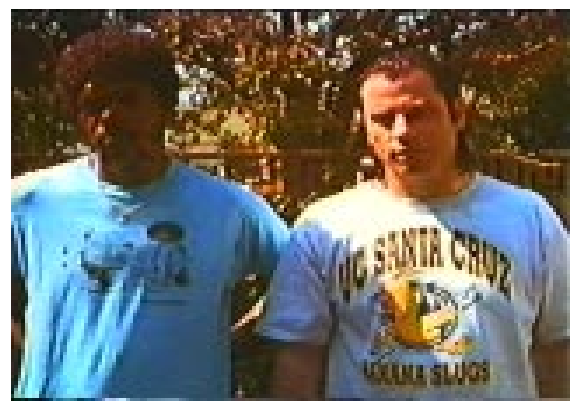

5. "The Bonnie Situation" mostra porque Vincent e Jules deixaram os ternos de lado. A sequiênda retoma 0 assalto à lancheria em seu fina. 
errado aqui? A história segue então o encontro de Vince e Mia Wallace (Uma Thurman) naquela noite. Jantam, vencem um concurso de dança e M ia tem uma overdose ao cheirar a heroína de Vincent. Recuperada após uma injeção deadrenalina no coração, MiaeVince se despedem.

A quartaparte, "TheGold Watch", começa na mesma noite(aparentemente), quando Butch ganha a luta que havia sido subornado para perder e precisa fugir de Los Angeles com Fabienne (Maria de Medeiros), sua esposa. Na manhã seguinte, Butch precisa voltar ao seu apartamento, ondebuscaráum relógio de seu pai. Sabe que devem haver capangas de Marsellus de tocaia em seu apartamento.

Chegando lá, encontra Vincent Vega saindo do banheiro. Mata Vega eao fugir do apartamento encontraeatropelaM arsellusWallace. Este não morre e começa a perseguir Butch até serem aprisonados por pervertidos em um subsolo de uma loja de penhores. Butch liberta ambos erecebeo perdão deMarsellus, desdequenunca mais coloqueos pés em $L A$. Butch aceita e vai embora com Fabienne.

A história então iniciasuaúltima parte, retrocedendo no tempo para a seqüência do acerto de contas.

Vemos que há um atirador escondido no armário que descarrega a arma em Vincent e Jules, mas não os acerta. Retornando para a base de trabalho, levam no carro um informante, Marvin. A arma deVincedispara por acaso e Marvin tem a cabeça explodida por um tiro.

Depois delimpar os estragos, Jules e Vincent estão vestidos de calção e camiseta, como haviam entrado em cena logo após o final da primeira cena de acerto de contas.

Se dirigem a uma lanchonete, a mesma queé assal tada na primeira seqüência do filme. Lá, confrontam-se com os Pumpkin e Honey Bunny, assumem o controle da situação evão embora. Vincentrumoa novostrabalhoscom

Figura 2: A estrutura de Pulp Fiction em ordem "cronológica".

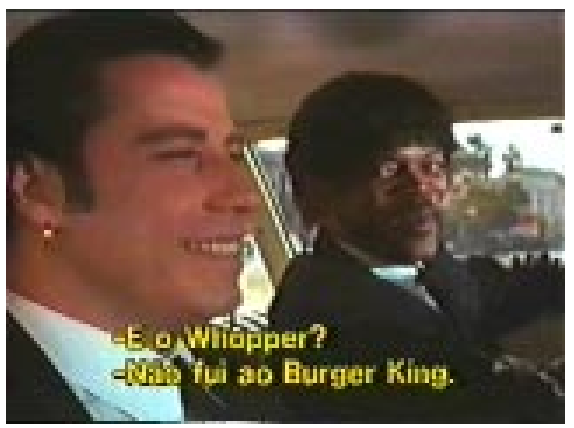

1. 0 filme

"começa" aqui: Jules e Vincent indo para 0 acerto de contas.

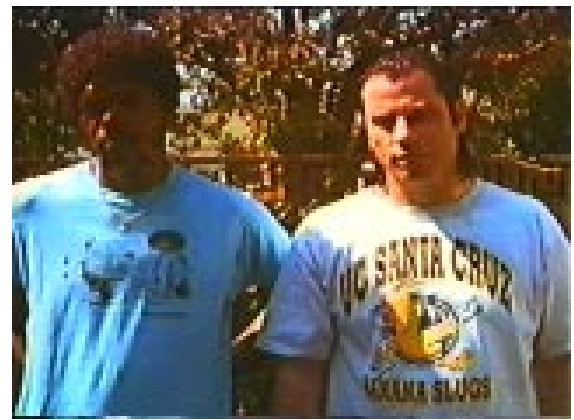

2. Depois do acerto, Vincent mata 0 informante por addente. Precisam limpar o carro onde etavam e trocar de roupa. Vão para a mesma lancheria ...

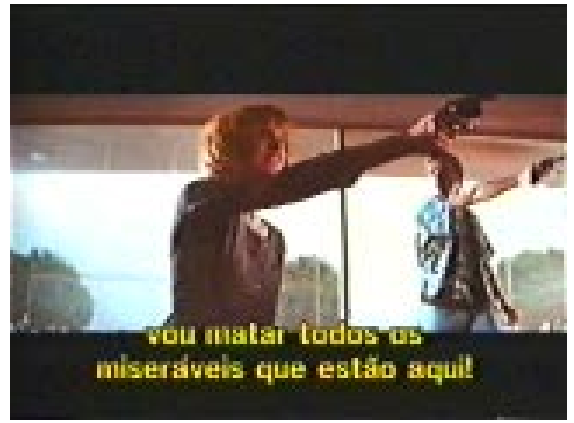

3. ... da cena de abertura, onde Pumpkin \& Honey Bunny estão prestes a encontrar bandidos de verdade.

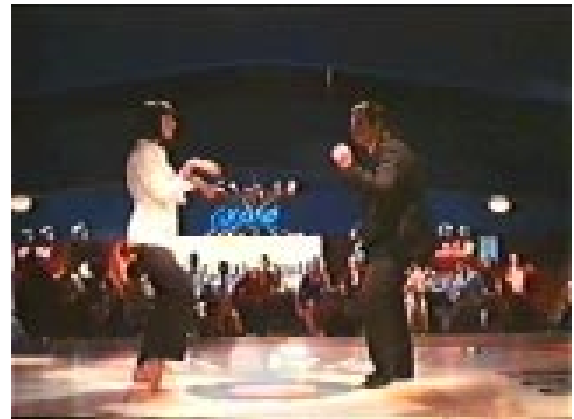

4. Vincent encontra Marsellus (de camiseta e calção) e recebe a missão de cuidar de Mia, esposa do chefe. Butch, o boxeador, é subornado aqui.

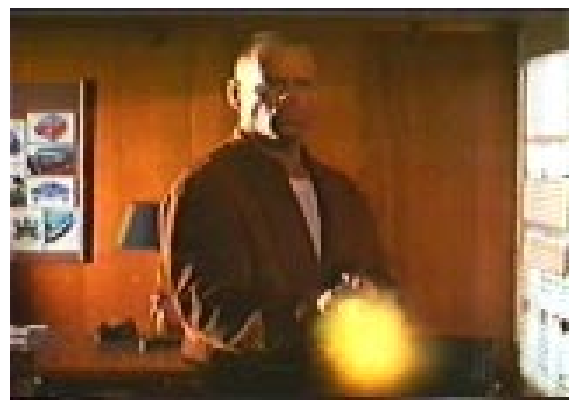

5. Butch não aumpre o trato e foge. Vince morre. Pervertidos prendem Marsellus e Butch, queliberta a ambos, e é perdoado por Marsellus. 
Marsellus. Jules, acaminho deumavidadiferente.

Reeditando Pulp Fiction

Algumas das surpresas de se assistir a Pulp Fiction vêm desua montagem queembaral ha as tramas no tempo, como foi descrito na seção anterior.

Todavia, ofilmepodeser reeditado com uma certa facilidade, colocando-se as histórias de umaforma "cronologicamentecorreta", como elas "teriam realmente acontecido". 9

A história se desenrola durante al guns dias. No início do filme "cronológico", Vince e Julesrumam parao acerto decontas cedo pela manhã. Um diálogo entre eles estabelece o horário:

"The two men stand in front of a door numbered '49'. They whisper....What time is it?

VINCENT (checking his watch):

- Seven-twenty-two in the a.m.

JULES

-Itain'tquitetimeyet, let'shangback."10

Depois do acerto decontas e do acidentecom o informante, trocam de roupa na casa de Jimmy (Quentin Tarantino), um amigo de Jules. Confrontamo assal to nalancheria, onde asfal as deH oney Bunny (A mandaPlummer) são diferentes na sequência mostrada no início da versão "oficial" e no final:

“HONEY BUNNY [no início]:

- Any of you fuckin'pricks move and I'll executeevery motherfuckin'lastone of you!" [esta éa que está no CD com a trilha sonora]

“HONEY BUNNY [no final]:

- Any of you fuckin'pricks move and I'll execute every one of you motherfuckers! Got that?"11
Depois do assalto, encontram-se com Marsellus Wallace. Como havia afirmado, Jules decide sair da vida de assassino profissional enão voltaaaparecer natrama. Vincent Vega recebe a missão de acompanhar a muIher de Marsellus, Mia, na noite seguinte, conforme o barman diz:

“ENGLISH DAVE:

- Comin'up. I hear you're taking Mia out tomorrow?

\section{VINCENT}

- At Marsellus' request."12

A luta de Butch que leva o filme "cronológico" ao seu final se passa alguns dias após a noite de Vega e Mia. Quando se encontram nos bastidores do ringue, junto ao boxeador queButch matou durantealuta, aconteceeste diálogo:

\section{“VINCENT \\ - Mia. How you doin'?}

MIA

- Great. I never thanked you for dinner."13

Na manhã seguinte, Vega e M arsellus estão emboscando Butch em seu apartamento. Butch mata Vincent coma arma deMarsellus e, após o aprisionamento na loja depenhores, ruma para a liberdade em uma Chopper.

Por que Tarantino escolheu fazer seu filme assim? Recursos deflashback eflash forward não são nada novos em narrativas cinematográficas, mas seu uso em Pulp Fiction deixa os espectadores desnorteados com os ladrões que somem após a seqüência de abertura, os personagens que morrem e reaparecem, etc. Lendo o roteiro, fica daro queisso foi planejado desde sua redação. Ainda assim, podemos remontar o filmeem grandes blocos, ${ }^{14}$ como se estivéssemos em um processador de textos. Com a palavra, Tarantino:

“QUENTIN TARANTINO: All right. I 
mean, the, the bottom line is, all right, my story line jumps all over the place.

CHARLIE ROSE: Right. Back and forward.

QUENTIN TARANTINO: In Pulp Fiction. Yeah, back and forward. And thething is, the truth of the matter is if I had written Pulp Fiction as a novel and I was on your show, you would never even remotely bring up the, the structure.

CHARLIE ROSE: Flashbacks ...

QUENTIN TARANTINO: ... of it.

CHARLIE ROSE: ... or whatever it was.

QUENTIN TARANTINO: You would, you would never bring it up, all right, because it's like, it - a novel can do that, no problem. N ovelists haveal ways had just a complete freedom to pretty much tell their story any way they saw fit, all right. And that's kind of what I'm- you know, that's kind of what I'm trying to do. Now, the thing is for both novels and film 75 percent of thestories you're going to tell will work better on a dramatic basis, on a dramatically engaging basis to be told from a linear way. But there is that 25 percent out there that, you know, can be more resonant by telling it this way. And I think in the case of both Reservoir D ogs and Pulp Fiction it gains a lot more resonance being told in this kind of like wild way." 15

O diretor e roteirista não está enganado em suas afirmações. Na maioria dos filmes modernos de $\mathrm{H}$ ollywood é possível identificar o que vai se desdobrar pela trama nos primeiros 10 ou 20 minutos da história.

Syd Field, renomado roteirista eprofessor de cinema, afirma:
“Dez minutos são dez páginas de roteiro. Esta primeira unidade de ação dramática é a mais importante do roteiro, porque vocêtem de mostrar ao seu leitor queméopersonagem principal, qual é a premissa dramática da história (do queelatrata) equal éasituação dramática (as circunstâncias em torno da ação)."16

Enquanto seguir tais regras não é de todo ruim (a indústria está fazendo mais dinheiro do que nunca, mesmo assim), isso deixa o campo aberto para quetal ordem seja questionada. E Tarantino soube aproveitar essa oportunidade muito bem. N as primeiras dez páginas dePulp Fiction temos a cena do assalto na lanchonete, que desaparece até o final do filme e o início do diálogo entre Jules e Vincent, a caminho do acerto de contas. A trama desvia-sedepoispara outrassubtramas (a noite com Mia, Butch) e somente "volta pros trilhos" no seu final. Isso é nãolinearidade narrativa?

Sim, mas ao estilo que uma mídia linear permita. Ou seja, acompanhamos as peripécias de Vincent e Jules sempre pelo olhar de Tarantino, como se estivéssemos lendo um jornal por sobre os ombros de alguém e não pudéssemosescolher quaismatériasou anúnciosler.

O formato da história tira partido da relação entre filme e espectador do cinema também. Tarantino sabia queteria o espectador fechado em uma sala por duas horas e meia a seu dispor. Podendo, portanto, sofisticar-se nos entrecortes entre as tramas que compõem Pulp Fiction.

Se ele fosse contar a história verbalmente é bem provável que dispersasse a atenção de seus ouvintes. Tente imaginar alguém contando a você a primeira frase de uma piada para então contar o início de outra e em seguida o final de uma terceira! Interagindo com o filmedeuma maneira diferentedaquela do simples espectador, é possível remontar o filme, conforme discutido anteriormente. 
Masisso ainda não faz de Pulp Fiction algo tão interativo ou não-linear quanto um jogo. $A$ percepção deque "háalgo dediferenteaqui" é justificada, mas devemos expandir a pergunta original "Pulp Fiction é não-linear?" para outra mais abrangente: "Como fazer de Pulp Fiction algo mais intensamentenão-linear?".

\section{Rumo à não-linearidade}

Há várias maneiras deconstruir uma história interativa. Todas elastêm em comumaintenção de possibilitar ao usuário al guma forma de criação ou intervenção na trama. Ao partirmos do terreno consagrado do chamado "roteiro americano" de Syd Field e tantos outros rumo a um campo de ebulição eincerteza como o das novas tecnologias de comunicação, alguns aspectos precisam ficar claros:

- Tornar histórias lineares em não-lineares envolve "personalizar" as histórias de acordo comquemaslê. Isso dissolveuma barreira antes absoluta entre autor e leitor, mas não nos dá a competência de um Fellini ou Tarantino automaticamente. Além disso, o tamanho da platéia diminui na maioria dos casos para apenas um, aquele que controla a narrativa efaz as escol has. ${ }^{17}$

- Criar narrativas com imagens em movimento é uma tarefa complexa, que exige de quem vai criá-la um conhecimento de uma "gramática visual" para garantir uma produção prazerosa para o espectador. A maioria das pessoas continua no nível das gravações domésticas em VHS.

- A variada gama de soluções que vemos surgir hoje em jogos e filmes experimentais expressa o problema fundamental dehistórias interativas: enquanto somente há uma forma socialmente aceita de interagir com um filme, hádezenas demaneiras deenvolver-se com uma históriainterativa. Vocêvai participar? Fazer o papel do herói? Passar segredos para o vilão? Envolver-se em batalhas? E como? Como mouse? O teclado? Sozinho? Em grupo? Ainda estamos vendo o nascer dessa forma de expressão, e ainda há muito caminho pela frente.

- Estamos tão acostumados com assistir a filmes no cinema etel evisão quenão percebemosnada entrenós, espectadores, e o espetáculo. Quando o filme captura nossa atenção, "voltamos à Terra" somente duas horas depois da viagem começar. É mais ou menos como andar debicicleta: vocênão pensa como mover os pedais, embora saiba como fazêlo inconscientemente. Da mesma forma, sabemos ler o filmeeentendêlo sem fazer grande esforço. Percorrer uma narrativa interativa exigeum novo aprendizado a respeito deseu funcionamento e regras. Enfim, como fazer para participar da história? Aquilo que era invisível éentão percebido. Temos, portanto, uma in terface entreo espectador eo espetáculo a mediar o relacionamento entreas partes.

Uma interface é algo que liga dois pontos distintos entre si, estabelecendo a possibilidade de comunicação entre eles. Como não estamos acostumados com o funcionamento dessa nova forma narrativa, estamos conscientes do processo de mediação e controle do andamento ao mesmo tempo que tentamosprestar atençãoàtramaquesedesenrola. Tentamos pensar enquanto pedal amos, eisso resulta em um aproveitamento limitado da narrativa. Quanto menos transparentea me diação, pior para o espetáculo.

O caminho da tela grande para a telinha de computadores e videogames é o rumo mais óbvio para encontrarmos narrativas interativas hoje em dia. Filmes como os da série Guerra nas Estrelasjá percorreram estecaminhoemultiplicaram-seemumasériedejogos dediferentes perfis. Nalnternetencontramos desdenarrativasnão-linearesrealizadascomo trabalho de conclusão no MIT Media Lab, quanto a ambientes onde os usuários assumem papéis e se envolvem em diferentes missões, como MUDs. ${ }^{18}$ 
Em uma migração do linear para o não- linear, Pulp Fiction passaria por adaptaçõesa novas formas deroteiro einteração com seus espectadores/ participantes. Emborasejaquestionável seissoseriadesejado-inclusivepor Tarantino! -, mostra como são abordadas as narrativas interativas hoje. Deuma forma geral, poderíamos colocar as narrativas em quatro grandesgrupos ${ }^{19}$ quanto aograu deinteratividade que permitem:

\section{a) $100 \%$ linear}

É oqueconhecemosnormalmente. O filmeno cinema ou na tel evisão, mesmo com os trejeitos não-lineares de Pulp Fiction. Ele foi construído para que você interaja com a narrativa de uma maneira bem definida.

Ainda que o papel do leitor não seja inteiramentepassivo, pois o sentido do filmeécompreendido de acordo com a mente de cada pessoa, as opções deinteração são limitadasa estabelecer o ritmo que deseja acompanhar a história (seestiver em um videocassete, através de pause, rewind, etc.) ou sair do cinema.

\section{b) Competitivas}

O primeiro passo acima da linearidade mistura seqüências denarrativalinear (vinhetas, esquetes, etc.) com partes da trama ondevocê precisa superar um desafio parafazêlaavançar. Jogos como Rebel Assault $11,{ }^{20}$ da LucasArts, são assim.

Neste jogo, você assume o papel do piloto R ookieO ne, quedevepassar por vários treinamentos e batalhas enfrentando o império galáctico. Entreosjogos deação há seqüências narrativas que dão mais detal hes sobre o que a pessoa vai enfrentar adiante, aprofundando a inserção do jogador no contexto. Se o jogador falhar, não há problema. Pode tentar de novo quantas vezes quiser. Enquanto não vencer a fase não vai adiante para conhecer mais planos de Darth Vader.
Colocar Pulp Fiction em um esquema assim seriapelomenosengraçado. O quesepoderia esperar deum filmeondeos heróis são "bandidos"? A pós o longo diálogo entre Vincent e Jules no carro antes do acerto de contas no início do filme, umjogo detiro ao alvo com os infel izes que estão no quarto 49? Depois um jogo dereani mação cardíaca deM ia Wallace? E que tal uma partida de boxe com Butch Coolidge?

A narrativa rica em detalhes de Pulp Fiction merece um modelo mais sofisticado para dar seus passos não-lineares. O modelo expresso acima sepresta mais a narrativas quepossam ser praticamente ignoradas para o desenvolvimento do jogo. Embora isso não fosseo caso com os filmes originais de Guerra nas Estrelas, conformeCampbell (1993), ${ }^{21}$ não éo caso deste jogo.

\section{c) Ramificadas}

Histórias interativas baseadas em ramificação podem ser resumidas em uma frase: uma entrada, muitas saídas. A partir de um ponto inicial, oleitor/ usuário vai tomando decisões que influenciam na trama, dirigindo-a para diferentes conclusões.

N avega-se, em narrativas destetipo, por uma infinidade de pedacinhos de narrativa. Há alguns anos, a Ediouro lançou uma série de livros deaventura emistério chamada “Agora Você Decide", baseada em um conceito semel hante. A pós ler al gumas páginas, o leitor era convocado a tomar uma decisão. Se fossea decisão $A$, rumaria para a páginax, se B, para a y , e assim por diante. As páginas eram embaral hadas para impedir que você lesse seqüencial mente a história.

Mais recentemente, jogos como Psychic D etective(Psygnosis, 1995), quemostramuma investigaçãolevadaadiantepor paranormais, continuaram a estender a teia de ramificação destetipo deestrutura. ${ }^{22}$ Estejogo édividido em 740 trechos de vídeo diferentes e ocupa 
três CD-ROMs. Seu roteiro ocupou 600 páginas.

Uma estrutura de ramificação estaria mais próximadetranspor Pulp Fiction comsucesso para meios não-lineares. Imagine que isso já tivesse sido feito. $O$ que vimos na tela teria sido então apenas um caminho, uma forma de explorar as ramificações. Seria possível percorrer a estrutura narrativa de maneiras diferentes, acessando informações quenão foram mostradas na edição porque acompanhamos Tarantino o tempo inteiro.

Produzir tal adaptação exigiria muito mais do roteirista, pois seria necessário contar o que está acontecendo e não está sendo mostrado naquelemomento, construindo inclusivemaneiras desepassar deuma história para a outra, mantendo a progressão dramática. A limitação da estrutura de ramificação é que embora abraum grandenúmero depossibilidades para interagir com a trama, não consegue abranger todas as existentes.

Imagine que, na cena onde Butch recebe o suborno de Marsellus e Vincent Vega chega ao bar, pudéssemos escolher entre acompanhar Butch para fora do bar ou escutar a conversa entre Vega e Marsellus. Seria fácil adicionar ainda a opção de conversar com o barman ou presenciar a conversa entreJulese Marsellus onde, aparentemente, elepededemissão. É várias vezes mais material para escrever e filmar, além de estragar algumas surpresas. Sedecidimos dar ao usuário a possibilidade de assistir a outros aspectos da trama, esses aspectos precisam valer a pena conhecer.

\section{d) Interação total}

Estamos cadavez nosafastando mais daquilo que era o filme original. Aqui, em vez de assistir, participamos da trama, assumindo o papel dediferentes personagens. $O$ roteirista tem a tar efa decriar os "caráteres" dospersonagens (queserão completadospelapersona- lidade de quem joga) e os ambientes onde o jogo se desenrola, com suas características próprias.

Jogar esse "Pulp Fiction RPG" sem dúvida se torna bastante distinto da experiência de assistir ao filme. Aqui as possibilidades da trama são apenas limitadas pelos jogadores que participam, bem como a duração da partida. Entrar em uma partida assim também muda a leitura sobre a narrativa, pois temos um ponto de vista de primeira pessoa o tempo todo. A estrutura costurada da versão cinematográfica de Pulp Fiction seria dissolvida assim, porque sempre seríamos algum dos personagens.

\section{Conclusão}

Pulp Fiction usa recursos de descontinuidade na trama para despertar o interesse do espectador, e o faz de uma maneira bastante competente. Ainda assim, foi feito em uma mídia essencialmente linear -o cinema- onde, se desejamos ter uma narrativa não-linear, precisamos mostrar para o espectador todos os caminhos, pois não há uma maneira deconstruir uma seletividade ou uma participação maior do público no cinema como o conhecemos hoje.23

Osmodel os denarrativa não-linear queestão mais definidos atéagora não seprestam para uma adaptação fácil de outros conteúdos. Assimcomo sabemosdadificuldadedeadaptar um livro ou uma peça deteatro para a tela, adaptar da tela para o mouse representa um desafio para o qual ainda não há soluções bem definidas. Este campo, todavia, tem recebido uma atenção crescente e novas estruturas denarrativa ainda estão por surgir.

\section{Notas}

1 Esucesso debilheteriatambém. Só nos EUA fez mais de 107 milhões de dólares de box office. No primeiro mês de venda, 0 vídeo vendeu 715 mil cópias, também nos EUA. 
Entertainment Weekly, 29/ 05/ 1995.

2 Outro cineasta que aprecia histórias próximas da nãolinearidade narrativa é Robert Altman. Em filmes como Short Cuts : Cenas da Vida, personagens entrecruzam seus caminhos, relacionando suas histórias de modo sutil.

3 EBERT, Roger. CINEM ANIA 97 CD-ROM. Microsoft Corporation. Redmond, 1996.

4 Histórias "pulp" não são desconhecidasno Brasil. O paulista José Carlos Ryoki de Alpoim Inoue está no Guinness Book por já ter escrito mais de mil livros "pulp" de faroeste e detetive, sob trinta e nove pseudônimos.

$50 \mathrm{~N}$ ew Y orker questiona a pertinência do título com relação a suas influências: "Despite its title, the movie owes far more to the Pop artists of the fifties and sixties than to the pulp writers of previous decades. The brackish streams of mood and motive that flowed beneath the works of James M. Cain and David Goodis may not have run deep, but they never ran dry; and the low-lit Los Angeles of Chandler is continents away from the garish, spasmodic town of Tarantino's fancy. Their only common currency is the knowledge that life is cheap". Anthony Lane, "Degrees Of Cool". The N ew Yorker. 11/ 10/ 94. Disponível na Internet via WWW. URL: http:/ / www.infinet.com/ dgeiser/ danspace/ movies/ quentin/ allthing/greatbig/ ne101094.txt. Capturado em 04/ 09/ 1997.

6 TARANTINO, Quentin. Pulp Fiction Screenplay. New York: Miramax Hyperion Books, 1994.

7 Filmes de episódios raramente dão certo. Na sua maioria parecem uma coletânea de curtas-metragens sem maior relação. 0 próprio Four Rooms (Grande Hotel), contando com bons atores e realizadores renomados (inclusive com um episódio de Tarantino), falha em manter o interesse do espectador.

8 Para os mais curiosos: 0 band-aid que Marsellus tem na nuca não tem um significado especial para a trama. Foi colocado ali porque 0 ator Ving Rhames tem uma cicatriz marcante ali, e isso desviaria a atenção do público. The Q uentin Tarantino FA Q .Disponível na Internet via WWW. URL: http:/ / www.artn.nwu.edu/ -stephan/ Tarantino.html\# Pulp_Fiction. Capturado dia 04/ 09/ 1997.
9 Nunca se pode cobrar verdade de uma obra de ficção, mas sim verossimilhança. Sabemos que não existe Luke Skywalker ou Darth Vader, e ainda assim acreditamos e nos divertimos com suas aventuras. Conforme Jorge Furtado, "Uma trama só precisa obedecer a sua lógica interna. Não à lógica externa." Jorge Furtado. Comunicação em Aula. Fundamentos de Cinema. 1993/ 2 FABICO-UFRGS.

10 TARANTINO, Quentin. Op. cit.

11 Idem, ibidem.

12 Idem, ibidem.

13 Idem, ibidem.

14 Se al gum leitor desejar experimentar reordenar o filme, é simples. Bastam dois videocassetes e um pouco de paciência. Assisti-lo torna-se menos divertido, inclusive porque o espectador não tem mais de "remontar" o filme mentalmente e lembrar-se das partes que já foram apresentadas.

15 Transcrição de entrevista a programa de TV. Disponível na InternetviaWWW. URL: http:/ / www.mind.net/ nikkoll/ text/ QTRose.html. Capturado em 04/ 09/ 1997.

16 FIELD, Syd. M anual do Rotero. Rio de Janeiro: Ed. Objetiva, 1995.

17 Mesmo em programas como "Você Decide", todos os miIhares de telefonemas são reduzidos a apenas uma opinião sobre a trama, como se ouvissem a apenas uma pessoa.

18 M ulti U ser Dungeon, um ambiente que recebe centenas de jogadores simultaneamente e os envolve em algum tipo de interação social como conversa ou ações colaborativas. Em geral era desenvolvido apenas com texto, mas passou a gerar crias que têm interfaces com desenhos e outros gráficos.

19 Adaptado da palestra deDI CASTRO, Andrea, no I Seminário de dramaturgia e interatividade. Fortaleza, abril de 1997.

20 Distribuído no Brasil pela Brasoft: http:/ / www.brasoft. com.br

21 CAMPBELL, Joseph. 0 Poder do Mito. São Paulo: Associação Palas A thena, 1993. 
22 VARCHOL, Douglas.M ultimediaS Criptwriting Workshop. San Francisco: Sybex, 1996.

23 Cinemas especiais, como al gumas salas desenvolvidas pela Sony em Nova lorque, permitem aos espectadores votar em determinados pontos de al guns poucos filmes, influenciando a narrativa. Outra vez voltamos ao ponto do "Você Decide": a opinião tem de ser sintetizada em apenas um ponto para poder ser computada. 